Research Article

\section{Prevalence of ESBL urinary tract infection in children}

\author{
Galia ZA Awean, Khalil Salameh*, Hala Elmohamed, Hoor \\ Alshmayt and Mohamed Riad Bur Omer \\ Dpartment of Pediatrics, Al Wakra Hospital, Hamad Medical Corporation, Qatar
}

\section{Background}

Urinary tract infection (UTI) is one of the extremely popular causes of febrile illness in children, demanding antimicrobial therapy [1]. Overall, $8 \%$ of females and $2 \%$ of males, experience at least one incident of UTI by seven years of age, and recurrence takes place in up to $30 \%$ during a year [2].

Escherichia Coli has been known as the commonest causative organism of the majority of urinary tract infections in children with prevalence ranging from 80-90\% [3]. Extendedspectrum beta-lactamases (ESBL) are enzymes produced by Gram-Negative Bacilli (GNB), accountable for fighting against penicillin, cephalosporin and aztreonam [4].

The prevalence of ESBL producing bacteria is dissimilar internationally, with varying records from North America, Europe, South America, Africa and Asia [5-7]. This is clinically significant, leading to increased risk of prescribing ineffective empirical therapy and augmenting resistance to antibiotics, which in recent years, turned into a leading trouble worldwide $[8,9]$, and correlating with intensified healthcare expense [10].

\section{The Objective of the Study}

\section{Primary objective}

To estimate the prevalence of urinary tract infection due to ESBL bacteria in children diagnosed with UTI and treated in Alwakra Hospital- HMC, Qatar.

\section{Secondary objective}

To identify possible risk factors that may predispose children to ESBL- UTI, such as age, recurrent urinary tract infection, frequent use of antibiotics, and underlying renal anomalies.

\section{Method}

A retrospective cross-sectional, descriptive study, estimating the prevalence of urinary tract infection due to ESBL producing pathogens in all children diagnosed to have UTI in AWH- pediatric emergency centre, outpatient clinics and inpatient between 1st January and 31 December 2016.

\section{More Information}

*Address for Correspondence: Khalil Salameh, Department of Pediatrics, Alwakra Hospital, Hamad Medical Corporation, Qatar, Tel: 0097440114258; Fax: (+974) 40114643 ; Email: Ksalameh@hamad.qa; ksalameh@hmc.org.qa; ksalame1@hotmail.com

Submitted: 05 August 2019

Approved: 07 August 2019

Published: 08 August 2019

How to cite this article: Awean GZA, Salameh $\mathrm{K}$, Elmohamed $\mathrm{H}$, Alshmayt $\mathrm{H}$, Omer MRB. Prevalence of ESBL urinary tract infection in children. J Adv Pediatr Child Health. 2019; 2: 004-007.

DOI: dx.doi.org/10.29328/journal.japch.1001004

Copyright: @ 2019 Awean GZA, et al. This is an open access article distributed under the Creative Commons Attribution License, which permits unrestricted use, distribution, and reproduction in any medium, provided the original work is properly cited

Abbreviation: UTI: Urinary Tract Infection; ESBL: Extended-Spectrum Beta-Lactamases; GNB: Gram-Negative Bacilli; AWH: Alwakra Hospital

\section{W) Check for updates}

The information was obtained from the electronic patients' records including age, gender, socio-demographic, vital signs (temperature and BP), admission to hospital, antibiotics use, results of urine culture, renal ultrasound and voiding cystourethrogram (VCUG) results.

The prevalence calculated as follows:

$$
\frac{\text { No. of Patients with ESBL UTI }}{\text { Total No. of patients with UTI }} \times 100
$$

\section{Inclusion criteria}

Patients age one day to 14 years, diagnosed to have urinary tract infection based on a positive urine culture growth of a single pathogen with more than 104 colonies forming unit (CFU/ ml) obtained by catheter, mid-stream urine sample, or any single colony for culture obtained by suprapubic aspiration.

\section{Exclusion criteria}

UTI based on urine culture obtained by other means than the above and culture result showing mixed growth.

\section{Hypothesis}

In children diagnosed to have urinary tract infection at $\mathrm{AWH}$, the prevalence of ESBL urinary tract infection is $15 \% \pm 5 \%$. 


\section{Statistical methods/analysis}

Categorical and continuous values were expressed as frequency (percentage) and mean $\pm \mathrm{SD}$ or median and interquartile range (IQR) as appropriate. Descriptive statistics were used to summarize demographic, clinical, laboratory, and other characteristics of the participants. The primary outcome variable is to identify and estimate the prevalence of ESBL-UTI in a patient diagnosed with UTI and determine possible risk factors that may predispose children to ESBLUTI. This was estimated and tested using appropriate Z test and the corresponding 95\% CI was computed to measure the precision of the estimate. Associations between two or more qualitative variables were assessed using the Chisquare $(\chi 2)$ test and Fisher Exact or Yates corrected Chisquare tests as appropriate. Quantitative data between the two independent groups were analyzed using unpaired' and Mann Whitney U tests as appropriate. Relationships between two quantitative variables were examined using Pearson's correlation coefficients. Univariate and multivariate logistic regression methods were used to assess the predictive values of predictors or risk factors for ESBL-UTI and results were presented and reported as odds ratio (OR) and associated $95 \%$ CI. All P values presented were two-tailed, and P values $<0.05$ was considered as statistically significant. All Statistical analyses were done using statistical packages SPSS 22.0 (SPSS Inc. Chicago, IL).

\section{Results}

Overall, 254 patients with non-repetitive urine culture results were diagnosed with urinary tract infection, 68(26.8\%) patients had ESBLs producing bacteria and 186 (73\%) patients had non-ESBL producing bacteria.

Escherichia coli was the most frequent isolated organism $170(66.9 \%), 55(32.4 \%)$ of them were ESBL producing. Klebsiella species, the second commonest cause responsible for $25(9.84 \%), 8(32 \%)$ of them were ESBL producing bacteria (Figure 1).31(29.8\%) of the patients are less than one year of age. Patient's epidemiology and sociodemographic characters are shown in table 1.

\section{Uine culture}

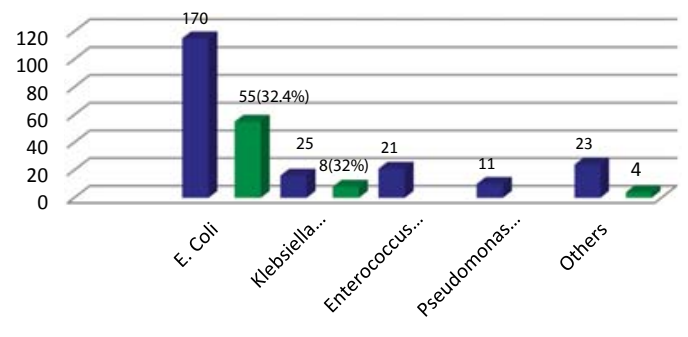

Bact. Non ESBL $\square$ Bact. ESBL

Figure 1: Escherichia coli was the most frequent isolated organism 170 $(66.9 \%), 55(32.4 \%)$ of them were ESBL producing. Klebsiella species, the second commonest cause responsible for $25(9.84 \%), 8(32 \%)$ of them were ESBL producing bacteria.

Table 1: Epidemiology, sociodemographic, lab and radiological characters of the patients with ESBL \& Non-ESBL UTI.

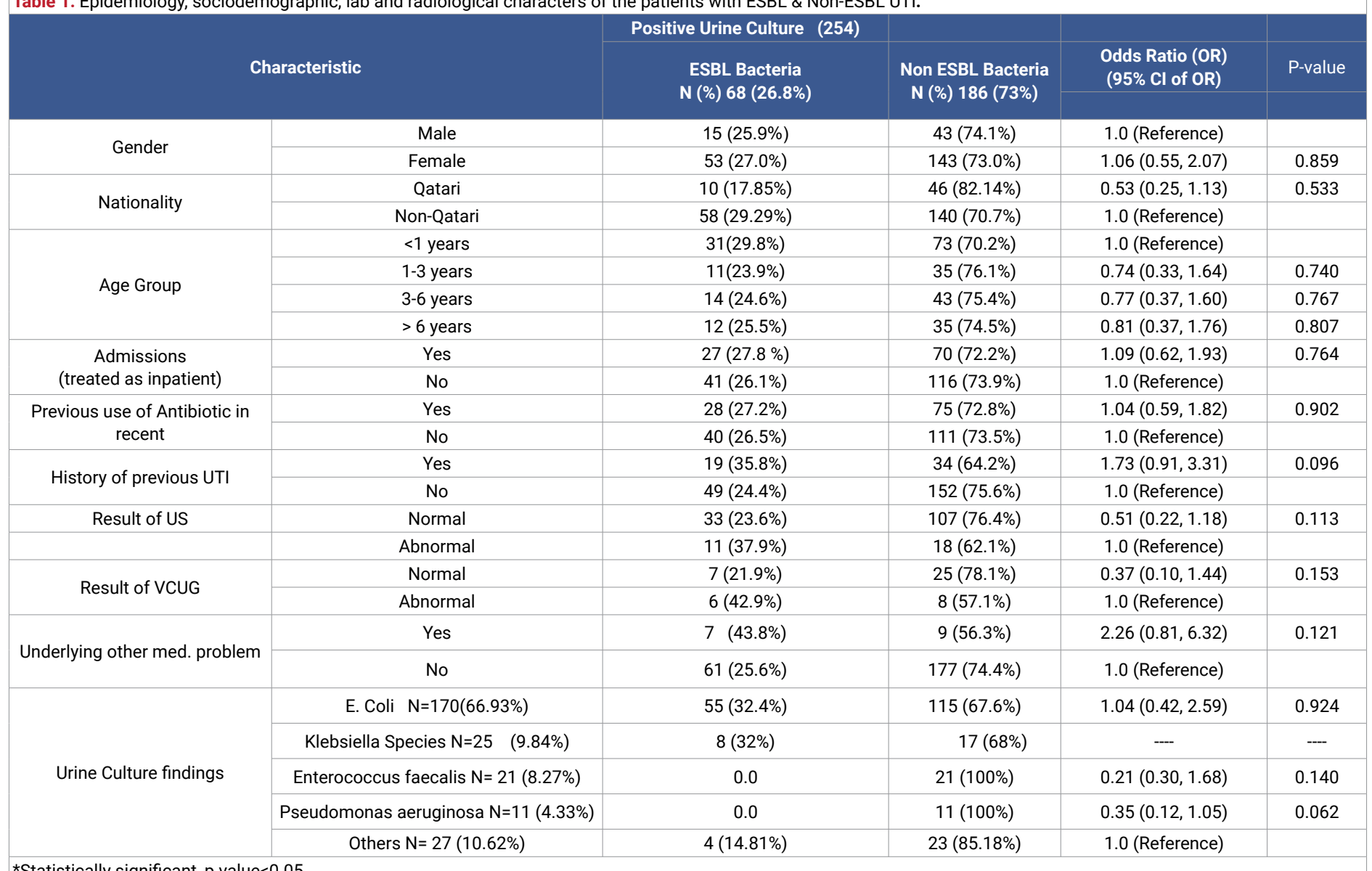

*Statistically significant, $\mathrm{p}$ value $<0.05$. 
27 (27.8\%) of patients with ESBL producing bacteria managed as inpatient and received intravenous antibiotics, while $41(26.1 \%)$ of them were managed as outpatients with oral antibiotics. $28(27.2 \%)$ of ESBL patients had taken antibiotics within 6 months and 19 (35.8\%) patients had recurrent UTI.

$7(43.8 \%)$ of ESBL patients had other underlying medical problems, the majority of them had spinal defect and neurogenic bladder.

Renal ultrasound is done in 44 patients with ESBL- UTI, 11 (37.9\%) were documented to have abnormal finding, most commonly in the form of pelvicalyceal system dilation. Voiding cystourethrogram (VCUG) was performed in 13 of ESBL patients. $6(42.9 \%)$ had vesicoureteral reflux grade1 to 5 .

Patient's laboratory and radiological characters for ESBL positive and non-ESBL, group are shown in table 1.

\section{Discussion}

ESBL-producing E.coli has been remarkably rising in recent years, especially in the community $[11,12]$.

In our study, the overall prevalence of ESBL-producing pathogens is $26.8 \%$, and the most common causative organisms were E.coli (66.93\%), (32.4\%), were ESBL, and Klebsiella Species (9.84\%), (32\%) were ESBL. This is comparable to other countries with prevalence in India of $37.7 \%$ [13], Iran $30.5 \%$ [14,15], Cambodia 44\% [16], and Turkey 41\% [17].

Our high prevalence could be explained because of the cosmopolitan population of children in Qatar with the majority been from the Indian subcontinent. The prevalence has risen as well in the developed world as represented in reports from Spain, $0.5 \%$ in 2000 to $4.04 \%$ in 2006, with an increase of 8 folds $[18,19]$. Latest data from the European Antimicrobial Surveillance System (EARSS) show cumulative rising in the detection of such strains. In 2010, the prevalence of ESBLproducing E.coli in Europe ranged from 2.6\% in Sweden to $24.8 \%$ in Bulgaria, with a prevalence of $12 \%$ in Spain [20].

From our cohort of patients, there are no statistically significant risk factors predisposing to infection with ESBL, producing bacteria with regards to patient age, previous use of antibiotics, recurrent UTI and underlying renal anomalies, (P $>0.05$ ), and also no significant statistical difference between the two groups regarding the association between the result of urine culture and abnormal renal ultrasound and or abnormal voiding cystourethrogram among results was reported in this study ( $\mathrm{P}>0.05)$, As well as on logistic regression analysis, were identified as independent risk factors.

This suggests that the high prevalence of ESBL strains in the community is the major influencing factor.

\section{Recommendation}

- Treatment of infection, should be restricted to those with documented growth on urine culture and subsequently tailored based on sensitivity results [21].

- Try to minimize the building up of bacterial resistance pattern.

\section{Acknowledgment}

The Medical Research Centre, HMC, for reviewing the research under the No. 17184/17. The publication of this article was funded by the Qatar National Library" Grant number: 0097455526390.

\section{References}

1. Zorc JJ, Kiddoo DA, Shaw KN. Diagnosis and management of pediatric urinary tract infections. Clin Microbiol Rev. 2005; 18: 417-422. PubMed: https://www.ncbi.nlm.nih.gov/pubmed/15831830

2. Desai DJ, Gilbert B, McBride CA. Pediatric urinary tract infections: Diagnosis and treatment. Aust Fam Physician. 2016; 45: 558-563.

3. Hanna-Wakim RH, Ghanem ST, El Helou MW, Khafaja SA, Shaker RA, et al. Epidemiology and characteristics of urinary tract infections in children and adolescents. Front Cell Infect Microbiol. 2015; 5: 45. PubMed: https://www.ncbi.nlm.nih.gov/pubmed/26075187

4. Cantón R, Valverde A, Novais A, Baquero F, Coque T. Evolution and current situation of ESBL. Enferm Infecc Microbiol Clin. 2007; 25: 2-10.

5. Bonnet R. Growing group of extended spectrum $\beta$-lactamases: the CTX-M enzymes. Antimicrob Agents Chemother. 2004; 48: 1-14.

6. Falagas ME, Karageorgopoulos DE. Extended spectrum $\beta$-lactamaseproducing organisms. J Hosp Infect. 2009; 73: 345-354.

PubMed: https://www.ncbi.nlm.nih.gov/pubmed/19596491

7. Reinert RR, Low DE, Rossi F, Zhang X, Wattal C, et al. Antimicrobial susceptibility among organisms from the Asia/ Pacific Rim, Europe and Latin and North America collected as part of TEST and the in vitro activity of tigecycline. J Antimicrob Chemother. 2007; 60: 1018-1029. PubMed: https://www.ncbi.nlm.nih.gov/pubmed/17855724

8. García-Hernández AM, García-Vázquez E, Hernández-Torres A, Ruiz $\mathrm{J}$, Yagüe G, et al. Bacteraemia due to Escherichia coli producing extended-spectrum beta-lactamases (ESBL): clinical relevance and today's insights]. Rev Esp Quimioter. 2011; 24: 57-66.

PubMed: https://www.ncbi.nlm.nih.gov/pubmed/21666996

9. Schwaber MJ, Carmeli Y. Mortality and delay in effective therapy associated with extended-spectrum beta-lactamase production in Enterobacteriaceae bacteremia: a systematic review and metaanalysis. J Antimicrob Chemother. 2007; 60: 913-920.

PubMed: https://www.ncbi.nlm.nih.gov/pubmed/17848376

10. Holmberg SD, Solomon SL, Blake PA. Health and economic impacts of antimicrobial resistance. Rev Infect Dis. 1987; 9: 1065-1078. PubMed: https://www.ncbi.nlm.nih.gov/pubmed/3321356

11. Colodner R, Rock W, Chazan B, Keller N, Guy N, et al. Risk factors for the development of extended-spectrum betalactamase- producing bacteria in nonhospitalized patients. Eur J Clin Microbiol Infect Dis. 2004; 23: 163-167.

PubMed: https://www.ncbi.nlm.nih.gov/pubmed/14986159

12. CLSI. Performance standards for antimicrobial susceptibility testing Nineteenth Informational Supplement. CLSI document M100-S19. Wayne, PA: Clinical and Laboratory Standards Institute. 2009.

13. Shettigar SCG, Roche R, Nayak N, Anitha KB, Soans S. Bacteriological profile, antibiotic sensitivity pattern, and detection of extendedspectrum $\beta$-lactamase in the isolates of urinary tract infection from children. J Child Health. 2016; 3: 5. 
14. Pourakbari B, Ferdosian F, Mahmoudi S, Teymuri M, Sabouni F, et al. Increase resistant rates and ESBL production between $\mathrm{E}$. coli isolates causing urinary tract infection in young patients from Iran. Braz J Microbiol. 2012; 43: 766-769.

PubMed: https://www.ncbi.nlm.nih.gov/pubmed/24031888

15. Rezai MS, Salehifar E, Rafiei A, Langaee T, Rafati M, et al. Characterization of Multidrug Resistant Extended-Spectrum Beta-Lactamase-Producing Escherichia coli among Uropathogens of Pediatrics in North of Iran. Biomed Res Int. 2015; 2015: 309478.

PubMed: https://www.ncbi.nlm.nih.gov/pubmed/26064896

16. Moore CE, Sona S, Poda S, Putchhat H, Kumar V, et al. Antimicrobia susceptibility of uropathogens isolated from Cambodian children. Paediatr Int Child Health. 2016: 36: 113-117.

PubMed: https://www.ncbi.nlm.nih.gov/pubmed/25704569

17. Kizilca O, Siraneci R, Yilmaz A, Hatipoglu N, Ozturk E, et al. Risk factors for community-acquired urinary tract infection caused by
ESBL-producing bacteria in children. Pediatr Int. 2012; 54: 858-862. PubMed: https://www.ncbi.nlm.nih.gov/pubmed/22882781

18. López-Cerero L, Pascual A. Epidemiology of ESBL in the community. An increasing problem. Enferm Infecc Microbiol Clin. 2007; 25: 23-28.

19. Hawser SP, Bouchillon SK, Lascols C, Hackel M, Hoban DJ, et al. Susceptibility of European ESCHERICHIA COLI clinical isolates from intra-abdominal infections, extended-spectrum betalactamase occurrence, resistance distribution, and molecular characterization of ertapenem-resistant isolates (SMART 2008-2009). Clin Microbiol Infect. 2012; 18: 253-259.

20. Rodríguez-BanñoJ,Navarro MD, Romero L, Martínez-Martínez L, Muniain $M A$, et al. Epidemiology and clinical features of infections caused by extended-spectrum beta-lactamase-producing ESCHERICHIA COLI in nonhospitalized patients. J Clin Microbiol. 2004; 42: 1089-1094. PubMed: https://www.ncbi.nlm.nih.gov/pubmed/15004058

21. Pediatric Urinary Tract Infection Organism-Specific Therapy. Updated: 2015. 